\title{
Quality Assessment of Aflatoxins Contamination in Red Chillies
}

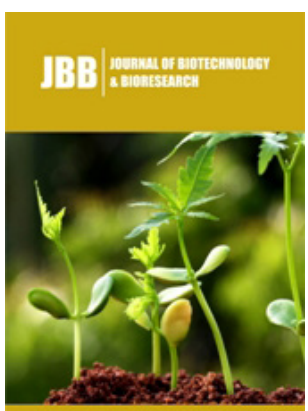

*Corresponding author: Naseem Zahra, Food and Biotechnology Research Centre, Lahore, Pakistan

Submission: 制 November 17, 2019

Published: 歱January 09, 2020

Volume 2 - Issue 3

How to cite this article: Naseem $\mathrm{Z}$ Imran K, Muhammad K S, Ijaz A. Quality Assessment of Aflatoxins Contamination in Red Chillies. J Biotech Biores.2(3). JBB.000537.2020.

Copyright@ Naseem Zahra,, This article is distributed under the terms of the Creative Commons Attribution 4.0 International License, which permits unrestricted use and redistribution provided that the original author and source are credited.

\author{
Naseem Zahra*, Imran Kalim, Muhammad Khalid Saeed and Ijaz Ahmad \\ Food and Biotechnology Research Centre, Lahore, Pakistan
}

\begin{abstract}
Quality assessment is very important for safe food surety. Aflatoxins are toxic and persuasive carcinogenic species and may harm human health badly. In the present study the quality assessment of aflatoxins contamination in red chilies was done by using TLC (Thin Layer Chromatographic) technique. Total 100 red chilli samples collected from various localities of Lahore were checked for aflatoxin contamination and the extent of aflatoxin contamination in the red chilli samples was found quite high. The aflatoxin B1 amount in samples ranges from min $0.2 \mu \mathrm{g} \mathrm{Kg}^{-1}$ to $\max 695.29 \mu \mathrm{gKg}^{-1}$ while aflatoxin B2 in samples ranges from $0.73-15.33 \mu \mathrm{gKg}^{-1}$. Aflatoxins G1 and G2 were absent in all samples. It was found that $88 \%$ of the red chilli samples were contaminated with aflatoxin and 64\% samples were containing aflatoxins beyond permissible limits. The results show a dejected condition of the red chillies which are unfit for human consumption. The supply of red chillies in Lahore, Pakistan is alarmingly dreadful for Humans health as aflatoxin may cause cancer when exceed permissible limits. The main reason for contamination of aflatoxins in chilli samples is the lack of implementing quality practices.
\end{abstract}

Keywords: Aflatoxin; Red chilli; Thin layer chromatography; Quality

\section{Introduction}

Food safety is essential for human survival. In the food sector, quality is a must for consumer recognition. Quality means that all the industrial procedures, manufacturing, and the final product are subjected to standard processing and conformance with requirements. Quality begins with the sustenance of superior management; involvement of all employees for the control of product quality [1]. In the present competitive environment, it is necessary for organizations to improve its overall performance and efficacy in achieving quality rank globally. The necessities in terms of information accessibility, risk preventative measure and control in the food sector is continued to increase [2]. It is necessary to incorporate safetyassurance systems to prevent contagion. There should be proper allocation of resources for dealing with threats and mishaps and to improve food quality [3,4]. Aflatoxins are noxious and carcinogenic derivatives produced as a result of the growth of the molds Aspergillus flavus and Aspergillus parasiticus and are majorly studied and generally identified mycotoxins [5,6]. Aflatoxins are classified in four major groups named as: Aflatoxin B1, B2, G1 and G2. The total AFLs: B1, B2, G1 and G2 permissible level is $20 \mu \mathrm{gKg}^{-1}$ for food and $50 \mu \mathrm{gKg}^{-1}$ for feedstuff. The permissible limit given by World Health Organization for total aflatoxin is above $30 \mu \mathrm{gKg}^{-1}$ [7]. Aflatoxin B1 is kept in Group I carcinogens by IARC (International Agency for Research on Cancer). The permissible limit for total aflatoxins in all food stuff is $20 \mu \mathrm{gKg}^{-1}$ [8]. The permissible limits of aflatoxins for chilli spices is $5 \mu \mathrm{gKg}^{-1}$ for AFB1 and $10 \mu \mathrm{gKg}^{-1}$ for total AFs $(\mathrm{B} 1+\mathrm{B} 2+\mathrm{G} 1+\mathrm{G} 2)$ according to the European Committee Regulations [9]. In chronic poisoning, aflatoxin is a threat to health and cause liver cancer but heightened intoxication of aflatoxins in human body is also fatal [10]. The developing countries are more susceptible to aflatoxin harmfulness due to lack of information and design of policies and strategies to control aflatoxin growth in food items. So, it is needed to design useful strategies for prevention from dreadful effects of aflatoxins [11]. Pakistan is sixth larger exporter of the red chillies all over the world. It is the matter of regret that European Union and Japan has banned the import from Pakistan due to large contamination of aflatoxins in Chilli [12]. In the current study, quality assessment of aflatoxins-the probable carcinogens in red chilli samples is done by collecting red chilli samples from various areas of Lahore. 


\section{Materials and Methods}

Aflatoxins were analyzed in different samples of red chilli collected from various areas of Lahore. Aflatoxins were determined in all the samples by Thin Layer Chromatography.

\section{Chemicals for aflatoxin determination}

In the present study, all the chemicals used were of analytical grade procured from BDH (Poole, England) and Merck (Darmstadt, Germany).

\section{Samples collection and storage}

Red chilli samples were collected from local market of Lahore city and brought to laboratory for quantitative determination. The amount collected of each sample was $1 \mathrm{Kg}$. The aflatoxins are not homogeneously distributed in chilli samples. In order to obtain the largest part of representative sample, an appropriate sampling way was adopted. The samples were passed through sample divider and were reduced to just about $200 \mathrm{~g}$ for the analysis purpose and thus a better homogenized portion of contaminated sample was achieved. Every sample was thoroughly mixed, grinded and converted to fine powder by sieving for investigational analysis. The samples were kept in airtight polythene bag for 2-3 days under controlled temperature $\left(24-26^{\circ} \mathrm{C}\right)$ and humidity $(53-55 \%)$ (Figure 1).

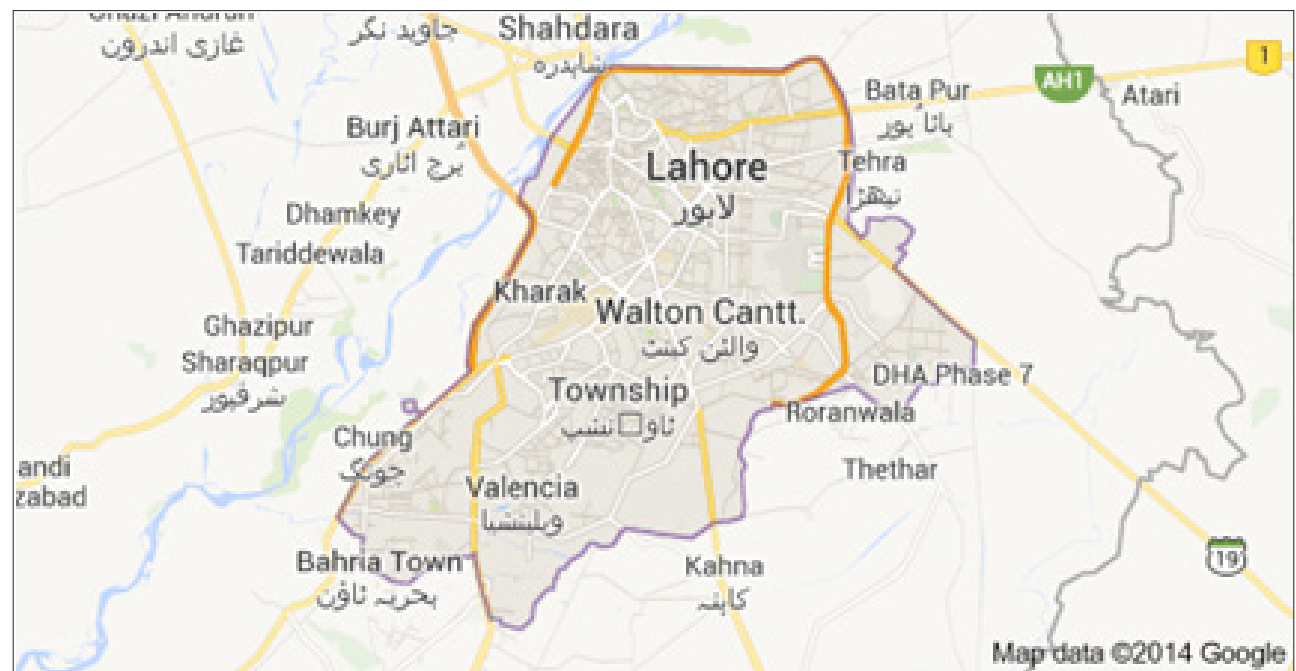

Figure 1: Map of lahore city.

\section{Aflatoxins determination in red chilli samples}

The presence of aflatoxins in red chilli was detected by using Thin Layer Chromatography (TLC) and UV Detector. Assessment of aflatoxins in toxic extracts was made by comparison with standards [13-18]. Thin Layer Chromatography (TLC) is a semi-quantitative method as powerful sample clean-up. TLC is simple to perform because aflatoxin fluoresce or absorb in the far UV region. It is rapid, an inexpensive separation technique [19]. Aflatoxins were extracted with chloroform which is most suitable method for aflatoxins (B1, B2, G1 and G2). 50g of pulverized sample was taken into $500 \mathrm{ml}$ conical flask and $25 \mathrm{ml}$ water and $150 \mathrm{ml}$ chloroform was added into flask. Conical flask was shaken on wrist action shaker for $30 \mathrm{~min}$. and sample was filtered through filter paper. $50 \mathrm{ml}$ filtrate was taken into beaker and put on steam bath for evaporation. Different spots of test solution were spotted on thin layer chromatographic plate and on the same plate aflatoxins standard was spotted [20]. The plate was developed with anhydrous ether in thin layer chromatographic tank up to till half. After development of plate from tank was removed and dried. Then plate was redeveloped in same direction in thin layer chromatographic tank with acetonechloroform [1:9]. Plate was removed and test solution spot was observed for presence or absence of aflatoxins under UV light. If preliminary plate would show that new concentration of test solution require then new concentration was prepared for spotting.

\section{Detection and estimation}

The test solution is evaporated to dryness on steam bath for quantitative determination and re-dissolved in calculated ratio of benzene-acetonitrile [98:2]. Successively spotting of 1.0, 3.0, 5.0 and 10.0, 15.0 and $25.0 \mu \mathrm{L}$ of test solution were made on TLC plate. All spots should be of approximately same size and on same plate spots of 1.0, 2.0, 3.0, 4.0 and 5.0 $\mu \mathrm{L}$ of aflatoxins standard were placed using micro syringe. Fluorescing intensities of sample spots were compared with those of standard aflatoxin spots. In case, fluorescing spot of sample lied between the standard spots, the average value of two standard spots was taken into consideration.

\section{Confirmation}

Another very important step in the aflatoxins analysis was the fluorescing sample spots. This was carried out by spraying evenly the thin layer chromatographic plate with aqueous sulphuric acid $(50 / 50 \mathrm{v} / \mathrm{v})$ after the spraying thin layer chromatographic plate was allowed to dry and then viewed under UV light (365nm). 


\section{Calculation}

Concentration of aflatoxins present in sample $\mu \mathrm{g} / \mathrm{kg}$ was calculated as follows.

Aflatoxins $\left(\mu \mathrm{ggg}^{-1}\right)=\mathrm{S} \times \mathrm{Y} \times \mathrm{V}$

$$
\mathrm{ZxW}
$$

Where,

$\mathrm{S}=$ Volume in $\mu \mathrm{L}$ of aflatoxins standard of equivalent intensity to $\mathrm{Z}$ ( $\mu \mathrm{L}$ of sample)

$\mathrm{Y}=$ Concentration of aflatoxins standard in $\mu \mathrm{g} / \mathrm{mL}$

$\mathrm{V}=$ Volume in $\mu \mathrm{L}$ of solvents required to dilute final extract

$\mathrm{Z}=$ Volume in $\mu \mathrm{L}$ of sample extract require to give fluorescence intensity comparable to that of $\mathrm{S}=\mu \mathrm{L}$ of aflatoxins standard

$\mathrm{W}=$ Weight in $\mathrm{g}$ of original sample contained in final extract
The concentration of Total Aflatoxins (B1, B2, G1 and G2) was calculated using following formula.

Total AFs=Concentration of AFB1+AFB2+AFG1+AFG2

\section{Results and Discussion}

The total number of 100 samples was analyzed for aflatoxin determination, out of which, 88 were contaminated and 12 were found not contaminated with aflatoxins which shows the prevalence of aflatoxins was quite high in the red chilli samples. Aflatoxin B2 was determined only in two samples. Samples with ID; Chilli-15-14 and Chilli-70-14 contain $15.33 \mu \mathrm{gKg}^{-1}$ and $0.73 \mu \mathrm{gKg}^{-1}$ aflatoxin B2 respectively. Aflatoxins G1 and G2 were absent in all the samples. The TLC results of Aflatoxin B1 are given in Table 1. There are 14 different aflatoxins which are produced in nature at least but Aflatoxin B1 is considered as the deadliest and it is produced by both molds i.e. Aspergillus flavus and Aspergillus parasiticus [21].

Table 1: Results of TLC for aflatoxin B1 Contamination level $\left(\mu \mathrm{gKg}^{-1}\right)$ in red chillies.

\begin{tabular}{|c|c|c|c|c|c|c|c|}
\hline Sr. No. & Aflatoxin B1 & Sr. No. & Aflatoxin B1 & Sr. No. & Aflatoxin B1 & Sr. No. & Aflatoxin B1 \\
\hline 1 & 248.66 & 23 & 4.32 & 45 & 2.90 & 67 & 66.69 \\
\hline 2 & 177.06 & 24 & 13.97 & 46 & 7.53 & 68 & 20.10 \\
\hline 3 & 63.90 & 25 & 4.33 & 47 & 30.69 & 69 & 23.62 \\
\hline 4 & 13.31 & 26 & 4.30 & 48 & 5.60 & 70 & 6.55 \\
\hline 5 & 26.56 & 27 & 12.56 & 49 & 15.01 & 71 & 30.09 \\
\hline 6 & 349.86 & 28 & 69.26 & 50 & 46.13 & 72 & 46.35 \\
\hline 7 & 1.31 & 29 & 23.76 & 51 & 20.05 & 73 & 11.51 \\
\hline 8 & 32.64 & 30 & 6.16 & 52 & 46.05 & 74 & 28.44 \\
\hline 9 & 19.16 & 31 & 12.98 & 53 & 15.04 & 75 & 160.29 \\
\hline 10 & 12.63 & 32 & 2.45 & 54 & 28.43 & 76 & 116.35 \\
\hline 11 & 14.71 & 33 & 4.41 & 55 & 18.97 & 77 & 3.76 \\
\hline 12 & 9.69 & 34 & 46.82 & 56 & 30.70 & 78 & 8.37 \\
\hline 13 & 11.55 & 35 & 2.45 & 57 & 22.63 & 79 & 327.00 \\
\hline 14 & 33.36 & 36 & 67.34 & 58 & 30.00 & 80 & 6.02 \\
\hline 15 & 357.30 & 37 & 1.64 & 59 & 46.20 & 81 & 11.71 \\
\hline 16 & 12.82 & 38 & 60.52 & 60 & 22.38 & 82 & 17.04 \\
\hline 17 & 695.29 & 39 & 22.27 & 61 & 46.26 & 83 & 23.98 \\
\hline 18 & 20.93 & 40 & 1.64 & 62 & 3.27 & 84 & 35.78 \\
\hline 19 & 12.85 & 41 & 1.31 & 63 & 7.56 & 85 & 17.12 \\
\hline 20 & 30.73 & 42 & 0.20 & 64 & 43.39 & 86 & 11.25 \\
\hline 21 & 132.94 & 43 & 2.05 & 65 & 28.5 & 87 & 11.06 \\
\hline 22 & 22.30 & 44 & 1.24 & 66 & 13.86 & 88 & 11.20 \\
\hline
\end{tabular}

\section{*N. D. $=$ Not Detected}

The results showed the alarming condition of red chillies supply in Pakistan. 88 samples (88\%) of the total samples were found unhygienic. Among contaminated samples 64\% had aflatoxins beyond the permissible limits whereas $24 \%$ had the aflatoxins below the permissible limits (Figure 2).

Total Number of Samples
Non-contaminated Samples $=$ Samples Contaminated with Aflatoxin B1 = Samples Contaminated with Aflatoxin B2 = Samples Contaminated with Aflatoxin G1 =
12

88

02

00 
Samples Contaminated with Aflatoxin G2 = 00

Permissible limit for Aflatoxin in Red Chillies $=\quad 10 \mu \mathrm{gKg}^{-1}$ Contaminated Samples exceeding Permissible Limits $=64$

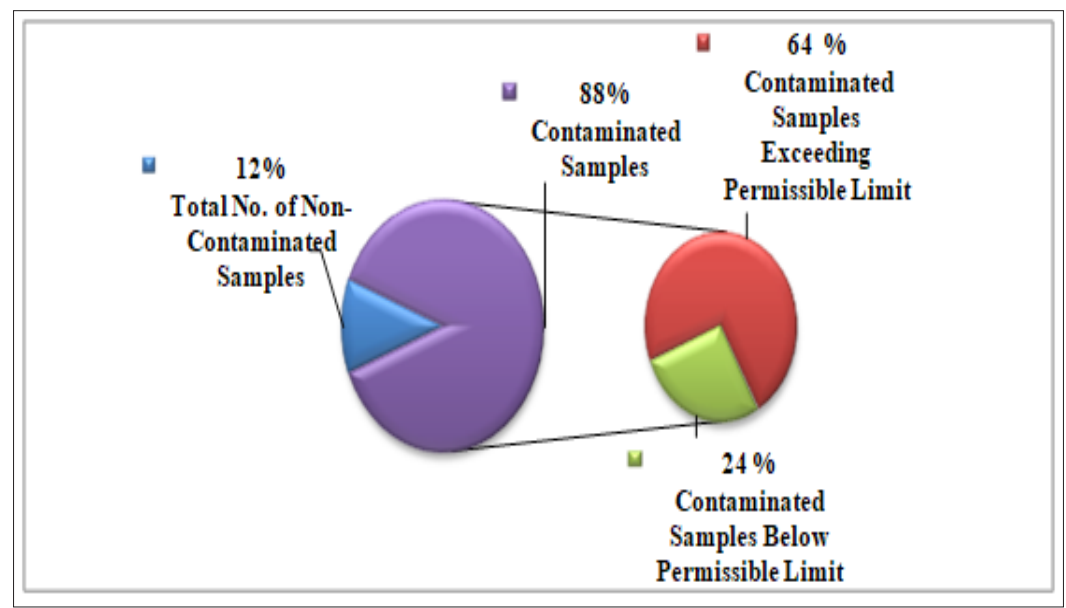

Figure 2: Percentage analysis of red chilli samples contaminated with aflatoxin B1.

The reason behind the presence of abundant aflatoxins in red chilli samples is the absence of food regulation authority in Pakistan. It may be a great health threat and a huge constraint on development in Pakistan. By the assistance of food regulation authority particular restrictions can be imposed on the supply of aflatoxin contaminated food commodities like red chillies. It was reported previously that the mean value for aflatoxins in red chillies was $5.6 \mu \mathrm{gKg}^{-1}$ [22]. The similar studies [23] on red chillies show aflatoxin contamination up to $30 \mu \mathrm{gKg}^{-1}$ maximum limit in $9 \%$ samples. The levels in the present study are too higher $88 \%$ and indicate a severe problem. Four types of aflatoxins were analyzed including aflatoxin type B1, B2, G1 and G2. Aflatoxin B1 is the most abundant type of aflatoxins with higher concentration whereas a few samples had aflatoxin B2. Aflatoxin types G1 and G2 were totally absent in all the samples. The sum of all the aflatoxins present in each of the red chilli samples determined the total of aflatoxin concentration.

Red chillies (capsicum indicium) are widely used in blended spices as well as in almost all sorts of foods and have got a complimentary approbation due to their extensive use for developing taste in food [24]. Aflatoxins were found in Indian snack foods which were developed without any processing [25]. According to WHO; the toxic limit for total AFs is above $30 \mu \mathrm{g} \mathrm{Kg}^{-1}$. China is the world's largest producer of red chilli as it produces 8.1 million metric tons in 2000. Turkey, India, Mexico, USA and Spain are also the major red chillies producing countries [26]. Aflatoxin is silent killer and its presence in red chillies in minor quantity may harm the health shoddily. Yet, red chillies contaminated with aflatoxins (AFs) have threatened the spice business. Improper drying, Poor harvesting practices, deprived handling, packaging, storage and transport of chillies aid fungal growth and hence, results in the augmented risk of AFs contamination. Aflatoxin contamination is inevitable and unpredictable which make it distinctive challenge to food safety as it directly or indirectly suffers human beings
[27]. From above study the distressing results regarding quality of red chillies were obtained. In order to improve the quality of red chillies; quality assessment and monitoring practices should be implemented austerely.

\section{Conclusion}

The present study conducted on some of red chilli samples shows that the contamination of the samples is because of lacking quality implementation. There must be precautionary measures against these detrimental toxins (aflatoxins) to avoid health issues in Pakistan. As red chillies are widely used in Pakistani Foods to add flavor and taste, so there should be restrictions on the supply of aflatoxin contaminated red chillies beyond the permissible limits. Proper monitoring and checking of red chillies is important to avoid aflatoxin contamination.

\section{References}

1. Andres JV (2005) Quality assurance for the food industry: A practical approach. In CRC press Boca Raton (Eds.), Washington DC: USA, pp: 1112.

2. Zhang Z, Waszink AB, Wijngaard J (2000) An instrument for measuring TQM implementation for Chinese manufacturing companies. International Journal of Quality and Reliability Management 17(7): 730755.

3. Yusof SM, Aspinwall E (2001) Case studies on the implementation of TQM in the UK automotive SMEs. International Journal of Quality and Reliability Management 18(7): 722-744.

4. Arumugam V, Ooi KB, Fong TC (2008) TQM practices and quality management performance: An investigation of their relationship using data from ISO 9001:2000 firms in Malaysia. The TQM Journal 20(6): 636-650.

5. Alim N, Naseem Z, Sajila H (2014) Detection of aflatoxins in rice samples. Bangladesh J Sci Ind Res 49(3): 189-194.

6. Lai X, Liu R, Ruan C, Zhang H, Liu C (2015) Occurrence of aflatoxins and ochratoxin A in rice samples from six provinces in China. Food Control 50: 401-404. 
7. Butler WH (1974) Review of the toxicology of aflatoxin. MRC Toxicology Unit, Medical Research Council Laboratories, Woodmansterne Road, England, pp: 217-222.

8. Liu YP, Yang LX, Yang NJ, Dong B, Cao LL, et al. (2012) Occurrence of fumonisins and aflatoxins in cereals from markets of Hebei Province of China. Food Addit Contam Part B Surveill 5(3): 208-211.

9. European Commission (2002) Commission Regulation No 472/2002 of 12 March 2002 amending regulation (EC) No 466/2001 setting maximum levels for certain contaminants in foodstuffs. Official Journal of the European Comm 75: 18-20.

10. Milita NM, Mihaescu G, Chifiriuc C (2010) Aflatoxins health risk factors. Bacterial Viruses Parazitol Epidemiol 55(1): 19-24.

11. Alim N, Naseem Z, Shamma F, Nusrat E, Sajila H (2012) Detection of aflatoxins in various samples of red chilli. Pakistan Journal of Scientific and Industrial Research 55(1): 27-29.

12. Abrar M, Anjum FM, Zahoor T, Nawaz H (2009) Effect of storage period and irradiation doses on red chillies. Pakistan Journal of Nutrition 8(8): 1287-1291.

13. Trucksess MW, Brumley WC, Nesheim S (1984) Rapid quantitation and confirmation of aflatoxins in corn and peanut butter, using a disposable silica gel column, thin layer chromatography, and gas chromatography/ mass spectrometry. J Assoc Off Anal Chem 67(5): 973-975.

14. Begum N, Adil R, Shah FH (1985) Contamination of groundnuts with aflatoxins. Pakistan Journal of Medical Research 24(3): 129-131.

15. Romer TR (1975) Screening method for the detection of aflatoxins in mixed feeds and other agricultural commodities with subsequent confirmation and quantitative measurement of aflatoxins in positive samples. J Assoc Off Anal Chem 58(3): 500-506.

16. AOAC (2005) Official methods of analysis of AOAC international- $\left(18^{\text {th }}\right.$ edn), Washington DC, USA.
17. Francis FJ (1999) Wiley Encyclopaedia of Food Science and Technology. $\left(2^{\text {nd }} \mathrm{edn}\right)$, Mycotoxin Analysis.

18. Lin L, Zhang J, Wang P, Yuesong W, Jiping C (1998) Thin layer chromatography of mycotoxins and comparison with other chromatographic methods. Journal of Chromatography A 815(1): 3-20.

19. Betina V (1985) Thin-layer chromatography of mycotoxins. J Chromatogr 334(3): 211-276.

20. Braic C, Puia C, Bodoki IE, Ocaciu C (2008) Screening and quantification of aflatoxins and ochratoxin in different cereals cultivated in Romania using thin layer chromatography. Journal of Food Quality 31(1): 108120 .

21. Boutrif E, Canet C (1998) Mycotoxin prevention and control: FAO programmes. Food and Nutrition Div, Italy.

22. MacDonald S, Castle L (1994) A UK retail survey of aflatoxins in herbs and spices and their fate during cooking. Food Addit Contam 13(1): 121128.

23. Reddy DVR, Therumala DK, Reddy SV, Walinger F, Mayo MA, et al. (2002) Food safety management in developing countries. Proceedings of the International Workshop, Montpellier, France.

24. Reyes EML, Gonzalez MEG, Vazquez TE (2011) Chemical and pharmacological aspects of capsaicin. Molecules 16(2): 1253-1270.

25. Banerjee M, Sarkar PK (2003) Microbiological quality of some retail spices in India. Food Research International 36(5): 469-474.

26. Alim N, Naseem Z, Yasha NB (2016) Comparative study of aflatoxins in brown rice samples of local and import quality. International Food Research Journal 23(1): 243-247.

27. Aydin A, Erkan ME, Başkaya R, Ciftcioglu G (2007) Determination of aflatoxin B1 levels in powdered red pepper. Food control 18(9): 10151018. 